\title{
A Marketing Approach to Conducting Successful Workshop-Based Programs for Faculty
}

\section{Linda Hilsen}

University of Minnesota-Duluth

Emily (Rusty) Wadsworth and Judy Cohen Northeastern Illinois University

Our purpose is to share what we have learned from our successes and failures conducting workshops for faculty. Although our programs are quite differently funded and focused, the reasons for our workshop triumphs and defeats are common. At the core of our successes has been a marketing orientation and the use of marketing devices (Note 1).

Some background about our programs will clarify the context in which we work. The University of Minnesota-Duluth (UMD) Instructional Development Service (IDS), initially funded by the Bush Foundation, will be supported by university monies as of July 1987. IDS serves 416 full-time faculty and administrators and 120 part-time faculty and teaching assistants. IDS has 1.0-1.5 FTE consulting staff who handle individualized and group consultations, the IDS Newsletter, minilibraries, and the program evaluation. A quarter-time secretary and administrative guidance from the Associate Vice Chancellor of Academic Administration complete IDS personnel.

The Professional Development program (PD) at Northeastern Illinois University (UNI) is modestly funded by the state. The UNI professional staff is composed of 376 full-time teaching faculty, 172 part-time instructors, and 171 chairpersons, administrators and professional support persons. PD's audience includes teaching faculty, librarians and counselors, 
and administrators up to the level of dean. Rusty manages the program as half of a mid-level administrative position. A secretary and two students complete the staff.

\section{A MARKETING ORIENTATION: THE KEY TO SUCCESSFUL WORKSHOPS}

The essence of a marketing orientation means meeting the needs of your audience or target market. Often, people in nonprofit organizations in their enthusiasm to "spread the word" feel they must "educate" their target market to need the services the nonprofit organization offers. "Education" takes the form of flashy advertisements and hoopla. This "selling" orientation is likely to fail or at best be a slow and expensive process. When professional and organizational development professionals use a marketing orientation to plan and implement workshops, they are likely to succeed because they are meeting a need the target market already perceives - IF there is a generic demand for workshops in the target market. Our experiences show that such a demand for workshops exists.

Marketing consists of four "p's": Product, Promotion, Place (in this case, where the workshop is held), and Price. Workshop marketing therefore consists of the workshop topic and its presentation, promoting the workshop, and the site of the workshop. If a fee is charged to attend the workshop, this is the "price" aspect of marketing. Since both at UMD and UNI no fees are charged, we will not address the price issue but will discuss each of the other three p's of marketing. Because the basis of marketing is meeting the needs of your target market, we first have to find out what those needs are-through marketing research.

\section{MARKETING RESEARCH: IDENTIFYING THE NEEDS OF YOUR TARGET MARKET}

Great food and a world famous presenter are liabilities if no one comes to your workshop. It is essential to know what your faculty wants and needs before you choose a topic.

To identify the needs and wants of your full constituency, formal marketing research methods should be used. These can be either qualitative or quantitative. With either technique, it 
is important to sample a cross-section of your target market to learn about the "silent majority" who have not actively participated in workshops before and/or have not volunteered their workshop interest.

At Northeastern, we conducted a qualitative needs assessment during the first year of the program. We identified a random, stratified sample of the population. The members of the Professional Development Advisory Committee interviewed the sample using the focused interview technique. Our aim was to identify the basic needs and values of our professional employees. We asked questions about how and why they chose academic careers, how UNI is different from what they expected or their ideal, whether or not they wished they were in some other career or university. We make sure that our workshop topics are appropriate to the values identified by the research and address the gap between the reality of academic work at UNI and the ideal as expressed by the interviewees.

The UNI constituency dislikes paper and pencil surveys; thus, we do not ordinarily attach our name to such instruments. Rather, we use quantitative data gathered by other units in the university and continue to interview.

At UMD, during IDS's start-up quarter, we sent a survey to the faculty inquiring about professional needs and interests from which a list of potential workshop topics was generated. (See Appendix A for a sample Faculty Needs Assessment Survey.) We supported and added to our survey data by talking with other schools and other POD members about their experiences with particular workshop topics.

Informal feedback also can help to identify topics of interest. On each evaluation form circulated after the workshops, we ask for suggestions for future workshop topics. All of our workshops have been initiated in response to faculty request.

In addition to using surveys, evaluation form suggestions, previous audience interests, and faculty requests, we keep up on all "hot" educational issues, both nationally and campusspecific. The topics are "there for the pickin" for program planners who LISTEN. We are out and about with our ears finely tuned to the campus grapevine to gather "soft" data. We teach. We lunch. We coffee. We LISTEN. We LISTEN. We LISTEN. We check our rumor data against our "hard" 
data and decide on a workshop topic. (See Appendix B for a listing of topics which have worked for us and others.)

\section{MARKETING YOUR WORKSHOP: PLANNING, IMPLEMENTATION AND CONTROL}

Now that you have identified the needs and wants of your target market, you can choose a topic that responds to the demand of your target market. Marketing activities occur in three steps: planning, implementation, and control. We will discuss each stage and the appropriate marketing p's (product, promotion, and/or place).

\section{Planning: Product}

The most basic product decision for a workshop is the topic. However, products consist of attributes which provide a "bundle of benefits" offered to your target market. These include an effective presenter who is well prepared (i.e., who knows your target market and therefore how to present and organize the workshop content for them). Other attributes include the right format and length of your workshop as well as the right date.

\section{Product: Choosing a Presenter}

Presenters can be nationally-known educators, peers within your institution, colleagues from other campuses, or yourself. All can turn out an audience if you correctly coordinate the workshop from beginning until end.

Whether you use someone from inside or outside will probably depend to a large extent on how much money you can spend. Of course, someone from inside is cheaper, maybe even free. Although some workshop coordinators believe that insiders may not attract as large an audience as outsiders, this has not been our experience. For example, if respected campus presenters are chosen and publicity is handled well, the audience number may be even greater for one of your own than for a national expert who is not well-known on your campus. If you are tuned to the grapevine, you should have some idea of people on campus who might be able to present the workshop. 
You can add to your list of names by posing your topic to department chairs, Student Affairs, and your speaker's bureau or public relations people.

If you decide to look outside of your university for a presenter, you may be able to find a reasonably priced expert in the same city or nearby. In doing so you will save on travel, housing, and other costs. Sometimes, you can even barter a workshop trade with an institution close to you. (This has been done in long distance situations on occasion; however, the problem is that, unless the trades can occur virtually simultaneously, university budgets tend to fluctuate, normally in a downward fashion, so that one of the two parties is cheated - -out of the opportunity to present elsewhere or by suddenly being a workshop short).

We have had tremendous good fortune in selecting effective presenters from outside our universities by attending conference programs of professional organizations such as POD, AAHE, and various disciplinary associations. You can also ask your own network of professional colleagues if they know anyone who might fit your needs.

Use extreme caution in accepting anyone else's suggestion. The most important piece of advice we can give you is, if at all possible, ONLY HIRE SOMEONE YOU HAVE ACTUALLY SEEN DO A PRESENTATION. Even hiring pleasant conversationalists whom you have met can be a mistake. Chatting and organizing an interactive, structured presentation require different skills. Hiring presenters who sound good on paper or over the phone or who worked for someone else often results in disaster. Whenever possible attend an individual's workshop before hiring the person.

If you are on a low budget or need to conserve the funds you do have, splitting the costs of a presenter with another department or service organization within your institution can result in savings for both. Another way to share costs is to work with other institutions in your local area. Two universities can split airfare and housing costs while each pays the consulting fee for the work performed on the site. You might consider a consortium arrangement in which each of the members selects workshop topics and presenters well in advance and exchanges their plans so that these resources and costs can be shared. 


\section{Product: Getting the Presenter Ready}

Except for some minor variations, both internal and external presenters need the same kinds of things to get them ready to do the workshop. Send the external presenter information about your campus so that she/he knows the important demographics. In a letter, identify the major current campus issues. For both internal and external presenters, identify those campus issues that may have an effect on the success of the workshop. Use the issues to get the presenter to focus the workshop to fit your institution's needs. If, for example, your university is in the middle of a major retrenchment which will affect faculty positions, the presenter of your career development workshop needs to know this.

In addition to issues, identify the kinds of activities the audience will expect. What works? What doesn't work? At both our schools the audience will expect to DO something rather than just sit there. On the other hand, at UNI faculty dislike activities that are personally revealing. Be sure, in any case, that the presenter works in some kind of networking, getting-to-know-each-other activity. As soon as you can, send the presenter the names of the people attending, their departments, and any other pertinent information.

On a more mundane level, set deadlines for having the presenter's handouts to you to be reproduced or agree that the presenter will provide the handouts. Well before the workshop, discuss what kind of $\mathrm{AV}$ equipment the presenter needs and how she/he would like to have the workshop room arranged.

If you are working with a consultant who is charging a fee, be certain you understand exactly what you are paying for. Have a clearly negotiated fee set well in advance; if budget constraints limit you, use your best Tijuana bargain-hunting skills. Are expenses included in the fee or added to it? If a presenter is doing a workshop one afternoon and repeating it the next morning, are you paying for two days' time? Can you expect that person to meet with other special interest groups or your staff while on campus? Settle these matters before the person sets foot on campus. Collect any needed information required by your university to establish a contract. Do not forget the Social Security number. Get all of the appropriate paper work done and done correctly so that the presenter can be paid as quickly as possible given the idiosyncrasies of your 
institution. Both you and the presenter must keep receipts for any allowable expense.

Usually for an external presenter, you also need to make arrangements for a place to stay, getting to and from the airport, and getting from one place to another on campus. Some people like to be alone the evening before they present; others do not enjoy solitude in a strange place and prefer to be entertained. Ask about your presenter's preferences and try to accommodate them. Send maps of the campus and city, enclose parking permits, or arrange to meet the presenter at the airport. Be certain your consultant knows where to park as universities are often reluctant to pay parking tickets.

If your workshop involves a panel of speakers, you face additional organizational responsibility in coordinating the preparations of several people. Begin working with the panel two months before the program. Make certain everyone has a fairly clear idea of his or her role by the end of the first brainstorming session. Give specific work assignments with due dates. Deadlines for materials to include in a workshop packet need to be set way ahead of the workshop date; one polished procrastinator can cause havoc in your busy pre-workshop life. As workshop time draws near, have a practice session with all present. As a courtesy and as a tranquilizer for yourself, talk to every presenter the day before the session to check last minute needs.

\section{Product: Choosing a Format, Length, and Date}

So, now that you have chosen your presenter, you must determine a time format which fits your audience's needs as it balances your presenter's abilities and time schedule. You must decide with the presenter how much time is needed to effectively address the topic. Remember to be sure that your presenter includes networking activities and uses an interactive style; let the participants participate. Workshops which are geared for a certain audience, say computer people, have their own set of demands. Hands-on experience may be a priority. In how-to workshops, participants benefit more if time is allocated for practicing the skill. Once your presenter understands the audience, the two of you will be able to determine the time needed to cover the topic and to propose some potentially effective formats. 
You know your audience better than anyone else. How much time can you expect them to commit for any single session: a full day, half day, one hour? Will they come if the weather is bad, good? Spend some time with your university's room scheduling and class scheduling people to determine the times during the week when the fewest classes are being offered. Repeat each workshop to attempt to reach as many faculty as possible. We have good success offering the same workshop during a mid-week afternoon and then repeating it the following morning. Wednesday and Thursday are particularly good days for workshops at UMD and UNI. Neither of us has good success with workshops in the evenings, on weekends, or on Mondays or Fridays. (Those workshop coordinators whose budgets are big enough to offer weekend retreat workshops at nearby plush resorts will, of course, disagree with our last statement).

You also must take your presenter's schedule into consideration when determining the dates and length of the workshop. How long can that person be away from his or her own classes, campus, job, family? Each topic, each presenter, each faculty must be considered carefully as decisions are made about format, length of presentation, and dates.

\section{Planning: Promotion}

A flashy or clever promotion campaign will not guarantee success of a workshop when that workshop does not meet the basic needs of the target market. On the other hand, if your topic meets the needs of the target market and if the target market is informed about what the workshop is about and what benefits it offers, the world may beat a path to your door. Appropriate promotion techniques include advertising (both direct mail and in university media), personal selling, and publicity. Another form of promotion, sales promotion, is designed to elicit response through incentives such as premiums. If you have a large budget, for example, you might offer coffee mugs with a workshop logo to participants. Since our budgets are more modest, we concentrate on other forms of promotion. We especially emphasize direct mail advertising and personal selling.

At the beginning of each term, we provide the faculty with a list of workshops for that term. Linda includes hers in the IDS 
Newsletter, giving an explanation of each workshop and a signup form (Appendix C). Although this does not get a high reply level, it alerts people to upcoming events. Rusty sends out a flyer with a list of the workshop titles, times and presenters for all of the workshops for that term. Ten days to two weeks before each workshop, send a flyer with a detailed explanation of what will happen at the workshop and a registration form. This is where you will get a good response if your workshop meets the needs of the audience and if you have made it sound like a worthwhile experience. The RSVP tear-off should include your return address, the workshop particulars, and blanks for the person's name, department, and telephone extension.

At UNI we use the same color and format for all workshop flyers. A yellow Professional Development Opportunity flyer means a PD event. UMD uses the same format for all workshops but color coordinates the flyers with the evaluation forms for each workshop to facilitate record keeping. Because you have been LISTENING to your constituency, you can begin your publicity with "in response to your request" or "returning by popular demand." In addition to your own flyers, advertise in in-house publications, student newspapers, and media when appropriate.

While you are out and about LISTENING to what your faculty is saying, you can also promote your next workshop. Make a special point to run into a person who you think might be interested in attending once you have made a personal invitation. Additionally, send a personal note or phone those people who might or should find the workshop useful.

Creating a series is a good way to keep regulars returning and to increase the number of participants. Word travels fast about quality presentations, so your audience builds with each additional member to your series. "Co-operative Learning," "Support for Computer-Based Instruction" and "Successful Instruction with ___ Students (Learning Disabled, International, Older-than-average, etc.)" have all worked for us. Although it is usually the topic which causes a faculty member to sign up and attend, some off-campus presenters can establish a following of their own based on previous presentations and will increase your attendance. 


\section{Planning: Place}

If modest budgets require that workshops take place on campus, the most basic decision regarding "place" has been made for you. Of course, you may have a choice of several campus locations to use. If you have such a choice or if your budget allows workshops off campus, the choice of location depends on appropriateness to the workshop topic (discussed below) as well as-you guessed it-the wants and needs of your target market. As with all aspects of marketing, the best way to learn the needs of your target market is through marketing research.

Minimally, the choice of the workshops site depends on the requirements of the workshop itself. As soon as you know your presenter's plans and topic, you can determine your room needs. The anticipated number of participants will determine room size. The workshop activities will determine the kind of seating needed, e.g., to break up into groups, you should have moveable chairs. If the presenter wants an overhead projector, you also need a screen; a blackboard, chalk; an easel, newsprint and markers. Try to find a room that is away from the hurly burly of students passing to classes and other distractions.

As soon as you know your room needs, schedule the room. Actually go look at it. Make certain that it will acommodate your physical set-up and AV needs. Don't assume because the room contains a phone that is a live line. A dead phone can put a real damper on a computer workshop using modems; check the line ahead of time. On your equipment list, type the phone number of the poeple who supply equipment. Make friends with the janitors. Find out where the dollies are. Schedule the room for one-half hour before and after the presentation.

If your budget allows, order food and drink for workshop participants. Standard fare for either morning or afternoon should include coffee, tea and Sanka, cold soda, and some kind of juice for the health conscious. When it is hot, you can safely eliminate hot drinks for afternoon sessions. The food should be "silent" because only the most rude will loudly crunch carrots and celery during a presentation. Sweet rolls, cream cheese and bagels, or cream cheese and nutbreads work well in the morning with the addition of "quiet" but firm 
fruits and cheese for the afternoons. Participants sincerely appreciate being treated in this fashion. In fact, food is a big budget item in many programs because it draws people and helps them socialize, which promotes your program. To entice pre-registrants, list the menu on the reminder memo which participants receive a day or two before the workshop. Besides the menu, include a "looking forward to seeing you at TIME in ROOM on DAY" statement. The reminder truly helps keep attendance equal to the number of pre-registrants.

\section{IMPLEMENTATION}

Now that you have planned your workshop, it is time to execute your plans. The day before the workshop have a list ready of everything that you will need the next day. Put the extension numbers of the janitors, food service, and AV center on the checklist. Gather all of the workshop materials and have them ready to go. Prepare a tote bag with workshop supplies such as extra markers, a nail file, a projector bulb, extra name tags, chalk, a stapler, pencils, paper, and anything else that you think might be necessary in an emergency. You would be amazed at how well a finger nail file can fix a faulty computer connection!

If you have pre-registered your participants, try to learn something about each one before the workshop which you can use in conversation. Of course, attempt to learn their names, departments, and faces so you can greet and introduce people on the big day.

Clear your schedule so that you are free for at least an hour before the workshop and so that you can stay afterwards as long as participants want to talk. Have someone available to run errands. Rusty brings a student assistant; Linda's secretary is on call.

\section{Implementation: Place}

Get to the room early. Set up a registration table. Arrange preprinted name tags in alphabetical order and neatly display any materials that you are giving to participants before the workshop begins. Do not include the evaluation form in the packet of materials; have it separate so people can fill it out 
before they leave. Have a sign-in sheet for everyone, but especially for a record of those who arrive but did not reserve space. Leftover preprinted name tags will tell you which pre-registrants did not attend. Verify that the food is there, that it is what you ordered, that it is attractively arranged. Have a waste container available for refuse. Determine if the phone works. Survey the AV equipment to assure yourself that what you ordered is there and functioning. Provide the presenter with liquid for consumption during the workshop. You should make certain your presenter has no obligations for at least an hour before the workshop for last minute prep time. Providing a secluded spot such as your office to review notes is a courtesy appreciated by the most practiced presenters. Your office should be empty because you should be doing last minute checks on everything.

\section{Implementation: Product}

You can maximize the benefits of your workshop by attending to the social function of the workshop as well as the learning function. Remember, part of the product includes packaging!

Ask someone else to "person" the registration table so you can greet people as they arrive. You will want to introduce your participants to each other as well. This is a good time to help people connect. Helping the presenter connect names with faces will promote participation during the workshop. Welcome those who have not pre-registered with open arms. Always have extra name tags available.

After people have had a chance to socialize, call the group together and begin. In your introduction you have an opportunity to promote your program. Explain the services your program offers: publications, workshops, opportunities for individual and group consultations. Thank the participants for attending and encourage them to help themselves to refreshments at the appropriate time.

When you introduce the presenter, say something that indicates that you have some sort of relationship with this person, e.g., "In our discussion last evening." If the presenter is from your campus, mention times that you have worked together before. Provide a brief introduction to the material 
the presenter will cover; build participants' anticipation, and turn it over to the person they are there to hear.

Your job is by no means done at this point. You must stay in the room to assist the presenter and participants in any way you can. Participate only if you do not detract from your registrants' experiences. Help circulate materials. Pass refreshment trays when appropriate. If the presenter breaks attendees into groups, assist in facilitating the groups whenever possible. If you run out of beverages, call food services immediately. Have extra pens and paper available for those who need them.

Have your campus photographer snap a few pictures during an interactive section of the workshop. These photographs can be put on display in a case or on a bulletin board. They will make those who attended feel important, make those who did not wish they had, and act as a publicity base for future endeavors.

When the presenter has completed the presentation, formally thank the presenter and the audience. Remind participants to complete the evaluation form. Mingle with those who are left discussing the workshop. Offer the presenter a cold beverage and congratulations.

Leave the facility in order. Take the time to thank all who helped you, from the janitors to the faculty person who helps you lug extra materials and equipment back to your office.

As soon as you return to your office, jot reminder notes for yourself. If workshop participants became interested in materials not available at the workshop, write this down so you can circulate copies of the article, book, video, or software. Before the presenter leaves campus, check with your secretary one more time to be certain financial forms have all the needed signatures and information.

\section{Control}

The "control" stage of the marketing process includes evaluating the success of your marketing strategy and using this new information to improve future marketing plans. The most basic information to gather for control is level of attendance. Our records allow us to identify both how many faculty have attended and who they are. Thus we know, for example, that at UMD from Spring 1984 to Fall 1986, 269 faculty members 
attended at least one workshop. These faculty represented disciplines in each of UMD's collegiate units. At UNI in a similar time span faculty from all but two departments in all three colleges, librarians, counselors, and administrators were represented among those attending workshops. Many of these individuals came to more than one workshop.

A more in-depth method of control is the use of evaluation forms. An evaluation form designed for each workshop allows you to include workshop-specific questions to determine if cognitive and affective goals were met. You can also gather information needed for evaluating the effectiveness of your program. Always leave space for workshop topic suggestions and additional comments.

The control stage of marketing is both the official completion of the workshop and the beginning of new marketing activities. Take the time to record original sign-ups, actual attendance, and returns of evaluation forms in your data base. Summarize evaluations and send the results to the presenter with a letter of appreciation. In the letter also be certain to ask if all financial commitments have been met.

If participants expressed interest in any follow-up groups or activities, conscientiously address their requests. Circulate materials of interest. Convene a follow-up discussion. Follow-up groups help achieve networking, promote your service and make faculty feel their needs are being met. Publish faculty reactions to workshops and provide the opportunity for major points to be shared by all faculty via your newsletter.

\section{CONCLUSION}

Identifying and striving to meet the needs of our constituencies rather than trying to sell them something that they don't want or value has been the most important part of the marketing approach to workshops for us. We have also found that the process orientation of marketing with attention to the " $3 \mathrm{p}$ 's" at each stage keeps us focused on the important things we need to know and do as we plan and present workshops.

Finally, we can't neglect to mention the most important "p", politeness. Remember every rule of courtesy your mother ever taught you because you will need to put them all to use to manage a workshop effectively. Without support, your workshop 
can fall apart before your very eyes. Be especially supportive to your secretary, the food service people, the room scheduler, the printer, the janitors, your presenter, and anyone you may have to call upon for help. If it is possible for anything to go wrong, it very well may-unless you follow the guidelines we have outlined. Good luck!

\section{NOTES}

1. The principles of marketing presented here are basic to marketing and can be found in any introduction to marketing textbook. Since most of us work in nonprofit institutions, Christopher $\mathrm{H}$. Lovelock and Charles B. Weinberg's Marketing for Public and Non-profit Managers (New York: John Wiley \& Sons, 1984) may be especially appropriate.

\section{APPENDIX A \\ Sample Faculty Needs Assessment Survey}

\section{Instructional Development Interest Survey}

As an initial step in implementing the Instructional Development Service, information is being collected concerning the interests and needs of the faculty. Please complete the following survey.

Name

Campus Address

Campus Phone

1. Are there particular topics you would like to have presented in workshops or lectures? If so, what are they?

2. Are you interested in participating in forums where your instructional theories and practices could be shared?

Are there specific topics you would like to discuss?

3. Are you interested in using the Individualized Consultation Service during the next year? Would you like more information about the Individualized Consultation Service? 
4. Please indicate in what areas you would like library materials on teaching expanded:

Classroom Approaches:

General overview

Presenting effective lectures

Leading discussions

Asking questions

Teaching large classes

Facilitating groups

Utilizing undergraduate and/or graduate teaching assistants Assisting disabled students in the classroom.

Learning Process and Theory:

General overview

Developmental stages

Critical thinking

Working with non-traditional students

Non-academic issues affecting student learning

Understanding the student of today

Sexism and racisim in the classroom

Technology in the Classroom:

Use of viedo tape

Computer assisted instruction

Instructional Aids:

Textbook selection

Developing syllabi

Test design

Writing test questions

Other:

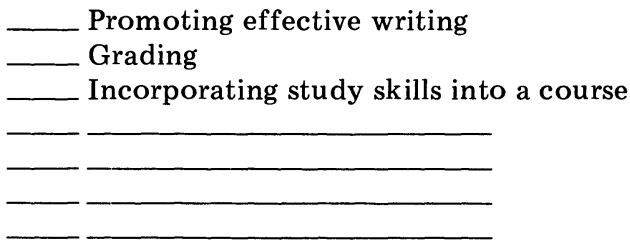

Do you have any additional suggestions, comments, or questions about the program?

Thank you for your time.

Please return this survey to:

Instructional Development Service Supportive Services Program

Library 134 


\section{APPENDIX B}

\section{Successful Workshop Topics}

\section{INSTRUCTIONAL WORKSHOPS}

The Classroom: A Chilly Climate for Women

Cultural Diversity: Issues and Opportunities

An Introduction to Microcomputers

The Art of Constructing Writing Assignments

Design and Construction of Computer-based Instructional Materials

Tips for Teaching Large Classes

Computer Generation of Tests and Test Scoring

Asking Questions and Stimulating Thinking

Discussion Techniques

The Feedback Lecture

Understanding Student Intellectual Development

The Computerized Grade Book

Students Working Cooperatively: A Powerful Way to Learn

Looking at Learning Styles

Achieving Educational Excellence

Support of Computer-based Instruction (series)

College Teaching and the Development of Reasoning

\section{PROFESSIONAL WORKSHOPS}

University Researcher's Network

Getting Published/Working at

Doing Research/Working at

Integrating Personal and Professional Growth

Career Planning for Faculty

Doing Scholarly Writing

Career Discussion Groups

Faculty Writing Support Group

Mid-life/Mid-career: Where do we go from here?

\section{PERSONAL WORKSHOPS}

Is There Life After Retirement?

Coping With Stress

Implications of the New Tax Law

Appealing Your Property Tax Assessment

Time Management

Intimacy and Personal Relations

Working/Living with Aging Parents 


\section{APPENDIX C \\ Sample Newsletter Advertisement}

\section{Upcoming IDS Workshops...}

Begin Fall Quarter right by treating yourself to some educational experiences!

\section{“SUCCESSFUL INSTRUCTION” SERIES CONTinues ... \\ SUCCESSFUL INSTRUCTION WITH INTERNATIONAL STUDENTS}

Presenters: Bob Kosuth - ESL. Instructor, English Department

Bruce Rutherford - International Student Advisor

Leane Rutherford - College Writing Instructor for International Students
Thursday, September 25
1:00-3:00 p.m.
Kirby 355-357

Fortunately, each year the UMD student population becomes culturally richer and more diverse. Approximately 200 international students will attend UMD this fall. To find the most effective methods to help all our students learn, we need to be educated in cultural differences and similarities. Heightened awareness will enable us to communicate information in understandable contexts.

Presenters will describe foreign students with reference to educational background, funding, and culture. Culture and logic as they affect writing and classroom performance will be explored. Reasonable expectations and appropriate standards for second language learners will be discussed. Awareness is needed by educators so adaptations can be made in the classroom to give all our students the best educational instruction possible.

\section{SUPPORT FOR COMPUTER-BASED INSTRUCTION SERIES}

Presenter: Dr. Stanley Trollip, Director of Project Assist

Department of Curriculum and Instruction

College of Education

University of Minnesota

Part I DESIGN CONSIDERATIONS for COMPUTER-BASED INSTRUCTION Wed., Oct. 8, 1:00-4:00 Kirby 355-357

or

Thurs., Oct. 9, 9:00-12:00 Kirby 355-357

The overall design characteristics that must be taken into account when constructing educational software will be discussed. Needs, instructional strategies, cognitive considerations, major methodologies, tutorials, drills, and simulations will be covered.
Part II AN INSTRUCTIONAL DESIGN MODEL Wed., Oct. 15, 1:00-4:00 Kirby 355-357 or Thurs., Oct. 16, 9:00-12:00 Kirby 355-357

A nine step design model which begins with the original conception of your idea and ends with an evaluation process for your completed project will be presented by Dr. Trollip, who has concentrated on the instructional uses of computers for the past 16 years. He will answer questions and guide you through this instruction design model.

\section{DETACH and RETURN TO:}

Linda Hilsen, Instructional Development Service, Lib 138

SUCCESSFUL INSTRUCTION WITH INTERNATIONAL STUDENTS

I plan to attend SUCCESSFUL INSTRUCTIONAL WITH INTERNATIONAL STUDENTS on September 25 from 1:00-3:00 in K355-357.

$\square \quad$ I have a conflict but would appreciate having this workshop repeated at a future time

\section{SUPPORT FOR COMPUTER-BASED INSTRUCTION}

I plan to attend Part I: DESIGN CONSIDERATIONS FOR COMPUTER-BASED INSTRUCTION. (Designate which session):

$\square \quad$ Wednesday, October 8 from 1:00-4:00 in K355-357

$\square \quad$ Thursday, October 9 from 9:00-12:00 in K355-357

I plan to attend Part II: AN INSTRUCTIONAL DESIGN MODEL. (Designate which session):

$\square$ Wednesday, October 15 from 1:00-4:00 in K355-357

$\square$ Thursday, October 16 from 9:00-12:00 in K355-357

NAME:

DEPT:

PHONE: 